\title{
Best practice for collar deployment of tri-axial accelerometers on a terrestrial quadruped to provide accurate measurement of body acceleration
}

\author{
Eleanor R. Dickinson ${ }^{1 *} \mathbb{D}$, Philip A. Stephens ${ }^{2}$, Nikki J. Marks ${ }^{1}$, Rory P. Wilson ${ }^{3}$ and David M. Scantlebury ${ }^{1}$
}

\begin{abstract}
Background: Tri-axial accelerometers are frequently deployed on terrestrial quadrupedal mammals using collars, because they are easy to fit and are thought to have minimal impact on the subject. Collar-attached devices are not fixed to the body and can move independently of the body. This may result in inaccurate measures of acceleration, reducing the accuracy of measured body movement. We determined the effect of collar size and collar weight on acceleration measured by a collar-mounted accelerometer on a quadruped mammal. The aim was to suggest best practice for sizes and weights of collars on which to deploy tri-axial accelerometers. Using pygmy goats, Capra aegagrus hircus, which were trained to walk at different speeds $(0.8-3.0 \mathrm{~km} / \mathrm{h})$ on a treadmill, we measured body acceleration using a collar-mounted tri-axial accelerometer, with different collar sizes (individual neck circumference $+1 \mathrm{~cm}$ to $+9 \mathrm{~cm}$ ) and collar weight ( $0.4 \%$ to $1.2 \%$ of individual weight).
\end{abstract}

Results: There was a significant effect of collar size, collar weight and walking speed on measured acceleration. Measured acceleration was less accurate and more variable when collars were looser and heavier. To measure body acceleration more accurately, we found that collar size should be within $5 \mathrm{~cm}$ or $16 \%$ of an individual's neck circumference when it was heavy (up to $1.2 \%$ of animal's body weight) or within $7 \mathrm{~cm}$ (33\%) of neck circumference if the collar was light (up to $0.6 \%$ of animal body weight).

Conclusion: We suggest that not only reporting collar size and weight for welfare purposes, but it is also important to consider these aspects for scientific rigour, to ensure data are collected as accurately as possible. We provide guidelines for researchers fitting collar-attached devices to ensure a higher degree of accuracy of recorded body acceleration.

Keywords: Tri-axial accelerometry, Terrestrial mammal, Collar-attached, Collar size, Collar weight, Pygmy goat

\section{Introduction}

Advances in biologging technology have led to the increased use of animal-borne tri-axial accelerometers to study domesticated and free-living animals [1-3]. This

*Correspondence: edickinson01@qub.ac.uk

${ }^{1}$ School of Biological Sciences, Queen's University Belfast, 19 Chlorine Gardens, Belfast BT9 5DL, Northern Ireland, UK

Full list of author information is available at the end of the article technology enables detailed information to be recorded about an individual's orientation and body movement [4]. Devices typically record acceleration data at high frequencies (e.g. $20-50 \mathrm{~Hz}$ ) in three axes which enables dynamic body acceleration to be calculated, such as vectoral dynamic body acceleration (VeDBA) $[5,6]$. Measured acceleration can be used to identify patterns of behaviour through analyses of body movement and orientation [7-10]. Body acceleration has also been shown

(c) The Author(s) 2020. This article is licensed under a Creative Commons Attribution 4.0 International License, which permits use, sharing, adaptation, distribution and reproduction in any medium or format, as long as you give appropriate credit to the original author(s) and the source, provide a link to the Creative Commons licence, and indicate if changes were made. The images or other third party material in this article are included in the article's Creative Commons licence, unless indicated otherwise in a credit line to the material. If material is not included in the article's Creative Commons licence and your intended use is not permitted by statutory regulation or exceeds the permitted use, you will need to obtain permission directly from the copyright holder. To view a copy of this licence, visit http://creativeco mmons.org/licenses/by/4.0/. The Creative Commons Public Domain Dedication waiver (http://creativecommons.org/publicdomain/ zero/1.0/) applies to the data made available in this article, unless otherwise stated in a credit line to the data. 
to correlate with oxygen consumption, and along with other movement-related metrics, can be used as an index of energy expenditure [11-13]. Furthermore, it can be included with other recorded data such as magnetic compass heading to infer movement paths of individuals by dead-reckoning [14].

The importance of correct attachment and positioning of biologging devices is broadly accepted, both for animal welfare considerations [15-17] and application purposes such as tag position to answer specific movement-related questions $[5,18]$. Generally, devices are attached to the subject's body, as close to the centre of mass as possible, and aligned so that the direction of measured axes is aligned with the organism's anatomical axes [19]. Such measures are easier to apply when attaching devices directly to the animal's hair or feathers using tape or glue, as is the case, for example, when attaching logging devices to marine mammals [20-22]. However, many studies utilise collar-attached systems, most commonly for deployment on quadrupedal terrestrial mammals [8, 23 ]. This moves the device away from the centre of mass, and unlike directly attached devices, collar-attached devices are not fixed to the body and may therefore move independently to the subject [19]. This may result in less accurate measurements of acceleration of the animal, and reduce the ability of accelerometry to determine behavioural patterns and body orientation.

Previous studies have proposed that in the interests of animal welfare, collar weight should not exceed $2 \%$ of body weight and collar size should be of appropriate tightness, dependent on the study species [17, 24]. A few studies have evaluated the effect of collar weight on the subjects' behaviour $[17,25]$ and investigated the welfare consequences of collar tightness [26]. However, the effect of collar size and weight on acceleration measured by a collar-attached device has not yet been quantified. These determinations are important because device weight is related to battery size and, therefore, to the period over which a device can record. Researchers may only have one opportunity to deploy a device, and thus, it is important to ensure that collar size and weight are optimal for accurate measurement of body acceleration.

We used African pygmy goats (Capra aegagrus hircus) as a model quadruped species to measure body acceleration of walking, measured via VeDBA over a second, at different speeds on a treadmill, which acted as a controlled environment. The main aims of this study were (1) to assess the effect of different collar sizes, ranging from 3 to $10 \mathrm{~cm}$ larger than the subjects' neck circumferences $(\mathrm{S} 1-\mathrm{S} 5)$, and weights, ranging from 0.4 to $1.2 \%$ of the subjects' body weights (W1-W5), on the measured acceleration of a collar-mounted device (Table 1); (2) to investigate the acceleration of a device acting as a control, positioned on the body of the animal using a harness so that the device is not subject to collar roll; and (3) to assess the effect of collar sizes and weights on the difference between acceleration measured on the collar and the harness. Selection amongst candidate general linear models (GLMs) used an information theoretic approach based on Aikake's Information Criteria (corrected for small sample size) $\left(\mathrm{AIC}_{\mathrm{c}}\right)$ [27]. Using predictions from the GLM output, we developed guidelines for relative collar sizes and weights, in order for future studies to measure body acceleration as accurately as possible.

\section{Results}

\section{Effect of collar size and weight on VeDBA}

The interaction between collar size and weight was retained in the model, positively affecting mean VeDBA $(\triangle \mathrm{AIC}=110.7$ relative to the best model that excluded the interaction) with higher mean values and more variation recorded on looser and heavier collars (Fig. 1; Additional file 1). For heavy and looser collars (S5, W5), VeDBA was predicted to increase twice as fast as that for

Table 1 Each measured combination of collar size (S1-S5), ranging from 1 to $9 \mathrm{~cm}$ greater than the animals' neck circumferences, and collar weight (W1-W5), ranging from 0.4 to $1.2 \%$ of the animals' masses, for the different goats (G01-G04)

\begin{tabular}{|c|c|c|c|c|c|}
\hline \multirow[t]{2}{*}{ Collar sizes } & \multicolumn{5}{|c|}{ Collar weights } \\
\hline & $\begin{array}{l}\text { W1 }(0.4 \% \\
\text { weight) }\end{array}$ & $\begin{array}{l}\text { W2 (0.6\% } \\
\text { weight) }\end{array}$ & $\begin{array}{l}\text { W3 }(0.8 \% \\
\text { weight) }\end{array}$ & $\begin{array}{l}\text { W4 (1.0\% } \\
\text { weight) }\end{array}$ & $\begin{array}{l}\text { W5 (1.2\% } \\
\text { weight) }\end{array}$ \\
\hline S1 (neck size $+3 \%$ or +1 cm) & G01, G02 & All & All & All & All \\
\hline S2 (neck size $+10 \%$ or $+3 \mathrm{~cm}$ ) & G01, G02 & G03, G04 & - & - & All \\
\hline S3 (neck size $+16 \%$ or $+5 \mathrm{~cm})$ & G01, G02 & G03, G04 & - & - & All \\
\hline S4 (neck size $+23 \%$ or $+7 \mathrm{~cm})$ & G01, G02 & G03, G04 & - & - & All \\
\hline S5 (neck size $+30 \%$ or $+9 \mathrm{~cm})$ & G01, G02 & All & All & All & All \\
\hline
\end{tabular}

All collar sizes were measured with the smallest and largest collar weight, and all collar weights were measured with the smallest and largest collar size, dashes represent collar combinations that were not measured due to study design. $0.4 \%$ of weight (W1) was not measured for goats G03 and G04 because the minimum weight of the collar was larger than $0.3 \%$ of body weight 
tighter and lighter collars (S1, W1 and W2). When the collar was loose but light (S5, W1 and W2), VeDBA was predicted to increase by more than two-thirds than if the collar was tight but heavy (S1, W5).

Collar parameters had an important effect on the relationship between VeDBA and animal travel speed (Fig. 2; Table 2; Additional file 1). There was a positive relationship between speed and mean VeDBA recorded from the collar-attached device. There were also positive interactions between collar size and speed and collar weight and speed retained in the model. There was no interaction between speed and goat ID; however, goat ID was retained in the model.

\section{VeDBA measured by the harness}

We investigated the relationship of harness-measured acceleration with the other variables to confirm that the relationship between acceleration and speed measured on the harness did not vary with different collar weights or sizes. There was a positive relationship between speed and VeDBA measured using the harness-attached device $(\triangle \mathrm{AIC}=578.6$ relative to the best model that excluded the interaction; Table 2) and goat ID was retained in the model. The effects of collar size and weight were retained. However, the interactions between speed and collar weight, or speed and collar size were not retained in the model $(\triangle \mathrm{AIC}=3.3$ and $\triangle \mathrm{AIC}=1.1$, respectively, relative to the best model that excluded the interaction). Showing that despite retaining collar size and weight in the model, it did not influence the relationship between acceleration and speed.

\section{Difference between collar and harness}

The interaction between collar size and collar weight was retained in the model, positively affecting difVeDBA (the difference between collar- and harness-measured acceleration), with a larger difference and more variation recorded when the collar was looser and heavier ( $\triangle \mathrm{AIC}=8.99$ relative to the best model that excluded the interaction; Table 2; Fig. 3). When collar size increased, the predicted increase in difVeDBA (g) per $\mathrm{km} / \mathrm{h}$ was up to four times greater for heavier collars than for lighter collars, and when collar weight increased, the predicted increase was up to three times larger for looser collars than tighter collars (Table 3; Additional file 1).

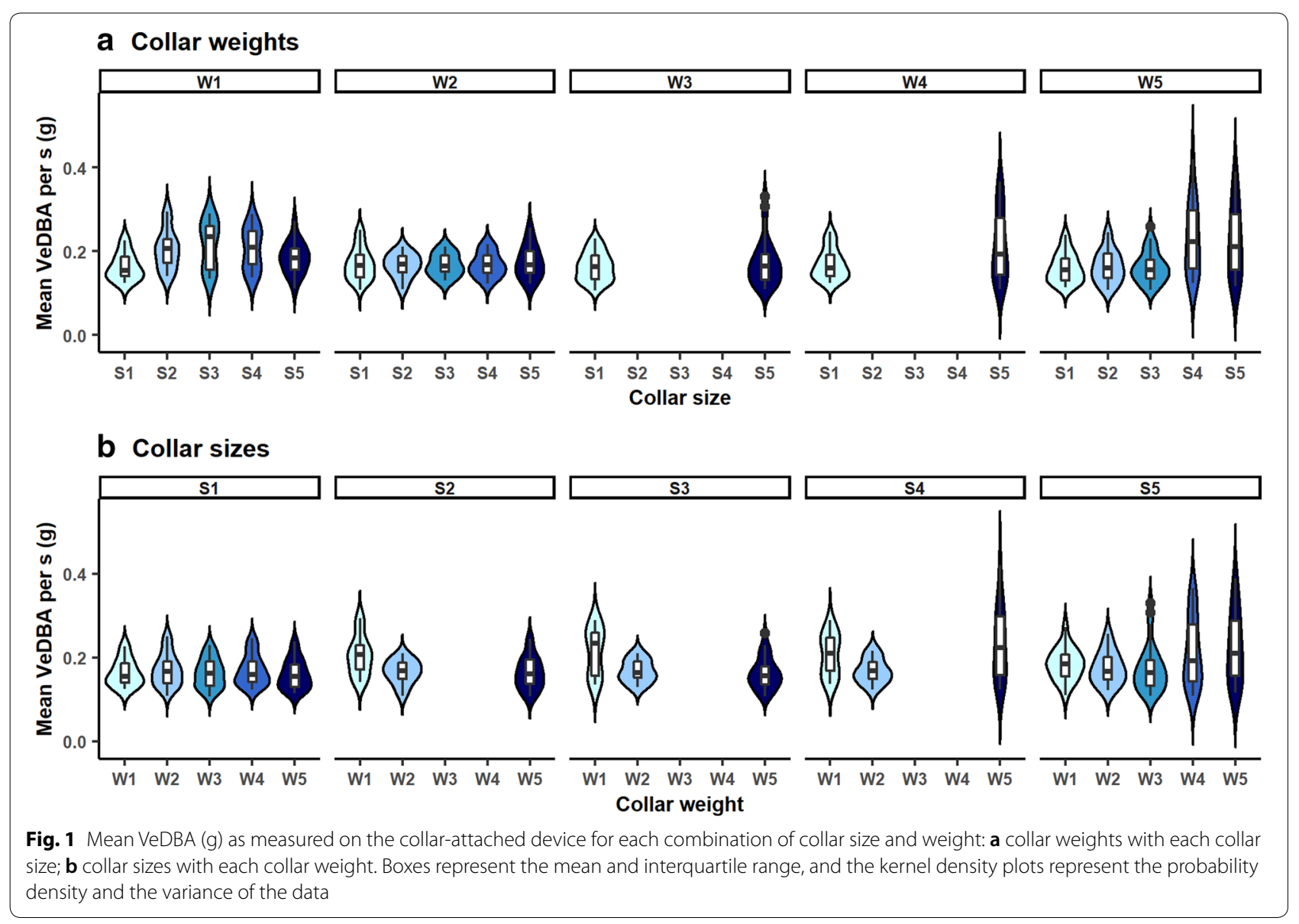



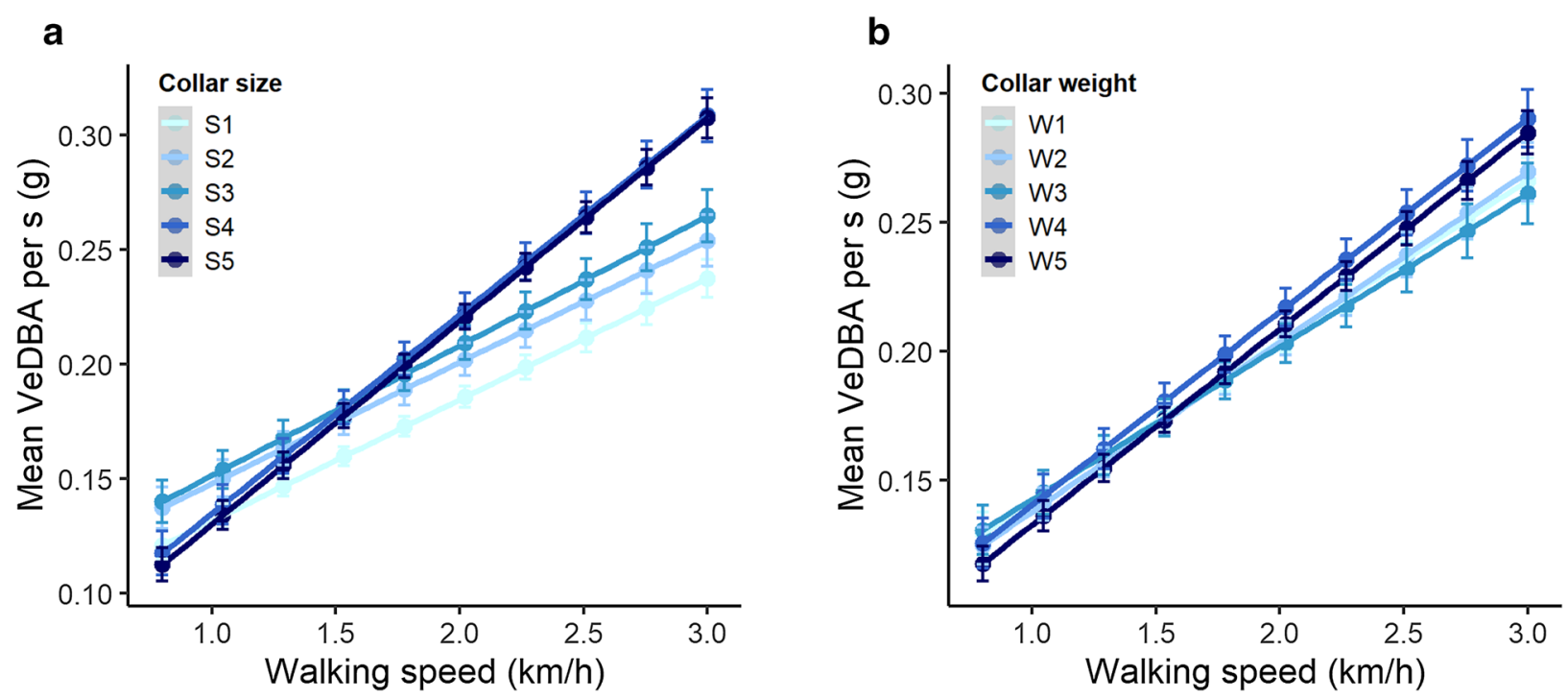

Fig. 2 The predicted relationship using the linear model between mean VeDBA $(\mathrm{g})$ and walking speed for $\mathbf{a}$ different collar sizes and $\mathbf{b}$ different collar weights. Fitted lines represent the predicted relationship and error bars represent predicted standard error

Table 2 The effect of collar size and weight on measured VeDBA, including the relationship between speed and goat ID as a fixed factor

\begin{tabular}{|c|c|c|c|c|c|}
\hline Candidate models and variables retained & $d f$ & logLik & $\mathrm{AIC}_{\mathrm{c}}$ & $\triangle \mathrm{AIC}$ & Weight \\
\hline \multicolumn{6}{|l|}{ 1. Effect of collar size and weight on VeDBA } \\
\hline$C S^{*} C W+C S^{*} S p+C W^{*} S p+G t$ & 32 & 1105.9 & -2142.7 & 0.00 & 0.522 \\
\hline $\mathrm{CS}^{*} \mathrm{CW}+\mathrm{CS}^{*} \mathrm{Sp}+\mathrm{CW}^{*} \mathrm{Sp}+\mathrm{Gt}^{*} \mathrm{Sp}$ & 35 & 1109.4 & -2142.5 & 0.18 & 0.477 \\
\hline \multicolumn{6}{|l|}{ 2. VeDBA measured by the harness } \\
\hline$C S+C W+G t+S p$ & 14 & 977.59 & -1926.2 & 0.00 & 0.437 \\
\hline$C S * S p+C W+G t$ & 18 & 981.38 & -1925.1 & 1.06 & 0.257 \\
\hline$C S * S p+C W+G t$ & 22 & 984.92 & -1923.4 & 2.79 & 0.108 \\
\hline$C S^{*} \mathrm{Sp}+\mathrm{CW} * \mathrm{Sp}+\mathrm{Gt}$ & 18 & 980.25 & -1922.9 & 3.33 & 0.083 \\
\hline $\mathrm{CS}+\mathrm{CW}+\mathrm{Gt} * \mathrm{Sp}$ & 17 & 978.64 & -1921.8 & 4.36 & 0.049 \\
\hline $\mathrm{CS} * \mathrm{Sp}+\mathrm{CW}+\mathrm{Gt} * \mathrm{Sp}$ & 21 & 982.69 & -1921.2 & 5.03 & 0.035 \\
\hline \multicolumn{6}{|l|}{ 3. Difference between collar and harness } \\
\hline$C S^{*} C W+C S * S p+C W^{*} S p+G t^{*} S p$ & 35 & 1092.1 & -2108.0 & 0.00 & 0.969 \\
\hline
\end{tabular}

Summaries of selected models for each with the AIC-best model are shown in italic. The fixed variables included in each model are collar size (CS), collar weight (CW), speed (Sp) and goat ID (Gt)

The extent of agreement between collar- and harnessderived estimates of VeDBA was negatively affected by animal travel speed as difVeDBA increased with speed ( $\triangle \mathrm{AIC}=260.1$ relative to the best model that excluded the interaction). There were significant interactions between speed and collar size (Fig. 3a) and speed and collar weight (Fig. 3b) on measured VeDBA. There was also a significant interaction between goat ID and speed.

\section{Discussion}

Our results indicate that the size and weight of a collar are likely to affect acceleration measured in animalborne tags. To ensure ethical deployment of collars onto subject animals, researchers must demonstrate that the best available techniques are being used that do not cause harm [16]. Therefore, in the context of animal welfare, it is also important to consider the effect of collar size and weight on the ability to measure the subject's body movement accurately. 


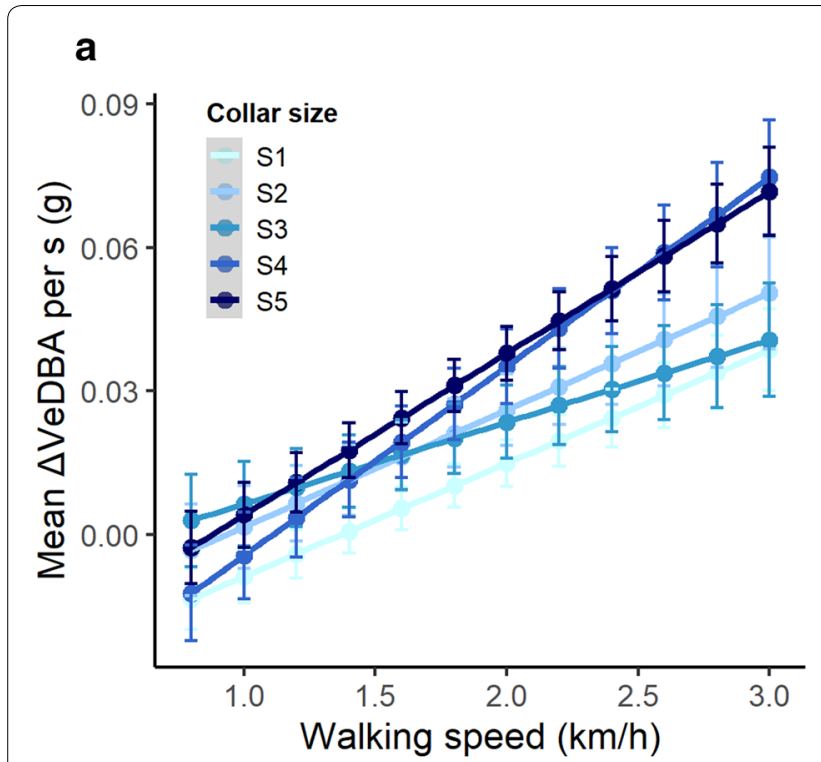

b

Fig. 3 The predicted relationship using the model output between the differences in mean difVeDBA ( $\mathrm{g}$ ), calculated as the difference between VeDBA measured on the collar and the harness, and animal walking speed for $\mathbf{a}$ collar sizes and $\mathbf{b}$ collar weights. Fitted lines represent the predicted relationship and error bars the predicted standard errors

Table 3 Predicted measured increase difVeDBA (g) per $\mathrm{km} / \mathrm{h}$ for each collar size (S1-S5) and weight (W1-W5) combination with predicted standard error

\begin{tabular}{llllll}
\hline Collar size & \multicolumn{2}{l}{ Collar weight } & & & \\
\cline { 2 - 6 } & W1 & W2 & W3 & W4 & W5 \\
\hline S1 & $0.013 \pm 0.007^{\mathrm{a}}$ & $0.017 \pm 0.005^{\mathrm{a}}$ & $0.014 \pm 0.06^{\mathrm{a}}$ & $0.030 \pm 0.005^{\mathrm{b}}$ & $0.044 \pm 0.006^{\mathrm{c}}$ \\
S2 & $0.014 \pm 0.007^{\mathrm{a}}$ & $0.018 \pm 0.008^{\mathrm{a}}$ & $0.015 \pm 0.01^{\mathrm{a}}$ & $0.031 \pm 0.01^{\mathrm{b}}$ & $0.045 \pm 0.006^{\mathrm{c}}$ \\
S3 & $0.010 \pm 0.008^{\mathrm{a}}$ & $0.011 \pm 0.008^{\mathrm{a}}$ & $0.010 \pm 0.01^{\mathrm{a}}$ & $0.023 \pm 0.01^{\mathrm{b}}$ & $0.038 \pm 0.006^{\mathrm{c}}$ \\
S4 & $0.029 \pm 0.007^{\mathrm{b}}$ & $0.033 \pm 0.009^{\mathrm{b}}$ & $0.030 \pm 0.01^{\mathrm{b}}$ & $0.046 \pm 0.01^{\mathrm{c}}$ & $0.060 \pm 0.007^{\mathrm{d}}$ \\
S5 & $0.023 \pm 0.007^{\mathrm{b}}$ & $0.027 \pm 0.008^{\mathrm{b}}$ & $0.024 \pm 0.006^{\mathrm{b}}$ & $0.040 \pm 0.006^{\mathrm{c}}$ & $0.054 \pm 0.007^{\mathrm{d}}$ \\
\hline
\end{tabular}

The size of the difference between values which represents the effect size of each combination is indicated; $<0.02^{\mathrm{a}},>0.02$ and $<0.035^{\mathrm{b}},>0.035$ and $<0.05^{\mathrm{c}},>0.05^{\mathrm{d}}$

Collars that are too tight may cause discomfort or injury and not account for potential animal growth, whilst collars that are too loose may ensnare the animal or be prematurely removed [28]. In line with ethical recommendations, we did not test collar sizes that are predicted to cause the animal discomfort [15]. Our results show, however, that the size and weight of the collar have a significant effect on the measured acceleration when the subject is walking. Tighter and lighter collars are more likely to provide more accurate measures of body movement, with smaller differences in effect size and variation between collar sizes S1 to S3 and collar weights W1 to W3. These collar parameters are also more likely to fit with ethical constraints. In contrast, looser and heavier collars are more likely to yield larger acceleration values and variation, reducing accuracy of measured acceleration. Collar sizes S4 and S5 with collar weight W5 were likely to have an effect size five times larger than the collar combinations $\mathrm{S} 1 / 2$ and $\mathrm{W} 1 / 2$.

This study also measured the interaction between collar size and weight. We found that if the collar is fitted tightly (neck $+5 \mathrm{~cm}$ or $16 \%$ of neck circumference), collar weight will have minimal effects on measured acceleration, see Table 2. As the increase in VeDBA is larger for heavier collars, it is recommended that when deploying collars heavier than $0.8 \%$ of body weight, collar size should be kept to within $5 \mathrm{~cm}$ or $16 \%$ of the subject's neck size. If the collar is looser (>neck $+5 \mathrm{~cm}$ ), then weight will have a larger effect; therefore, if this size is used, researchers should consider using collars within $0.6 \%$ of the subject's body weight. The fact that the effect of collar size was smaller than that of weight demonstrates that 
size is important to consider but, within $16 \%$ of neck circumference, is less likely to affect measured acceleration significantly. Changes in body mass must be considered when deploying collars, as many ungulates undergo substantial body mass changes seasonally, affecting collar tightness with the potential to cause harm to the subject $[26,29]$. Therefore, collars should be deployed that are neither too tight nor too loose in proportion to the neck size of the subject to satisfy ethics and provide accurate measurement of relative body acceleration. Of course, this study does not address body mass changes; considerations in relation to this must be made for any given study species.

This study measured the effect of collar weight within $1.2 \%$ of the subject's body weight. The commonly suggested ' $5 \%$ (or $3 \%$ ) rule' has been suggested to be arbitrary [24]. However, studies investigating the effect of logger weight have mainly focused on flying animals [30, 31]. On terrestrial mammals, it has been suggested that $2 \%$ is more appropriate for collar-attached devices [15], and even an increase from 0.4 to $0.6 \%$ in collar weight has been shown to affect the behaviour of a large ungulate [25]. This study shows that when using collar-attached devices to measure body movement, weight has an effect on measured acceleration. It is important to consider device weight for both measurement accuracy as well as considering its potential influence on behaviour.

The effect of collar size and weight also varied with walking speed: at low speeds, there was little variation between collar sizes and weights, but at higher speeds, variation increased [19]. Wild animals are likely to display a wider range of behaviours and larger accelerations than in our controlled experimental setting, depending on the species' body size and characteristics of their body movement $[10,23]$. The larger variation in these behaviours may be exaggerated by collars that are loose and/ or heavy; therefore, in a normal setting, the observed effects of collar size and weight might be larger and more variable. It is, therefore, important to consider that this effect may be different in behaviours other than walking. Furthermore, when applying these recommendations to other species, it is important to consider other factors such as body shape and differences in movement, making deployment decisions based on the study species in question.

\section{Conclusions}

This study highlights that both the size and weight of the collar affect measured body acceleration in a quadrupedal terrestrial mammal. The importance of correctly fitting a collar for deployment of devices that record body movement, to ensure the highest standards of both welfare and scientific precision, is highlighted. We recommend that collar tightness be kept to $+16 \%$ of neck size and collar weight to be kept within $0.8 \%$ of the subjects' body mass. If the collar is tighter than this $+16 \%$ guideline, collar weight will have less effect, and thus, heavier collars will not have a negative effect. We suggest consideration of these recommendations when deploying collar-mounted devices and that researchers should report the size and weight in research outputs to demonstrate best practise and enable similar studies to employ comparable and reproducible methods.

\section{Methods}

\section{Study animals}

The study took place in June 2018 at Belfast zoo, within the subjects' normal housing area. Four female adult African pygmy goats were used (body weight: 13.5$23.1 \mathrm{~kg}$; Table 4), as they are easily trained domesticated caprids amenable to the use of collars and harnesses. Using positive reinforcement, consisting of the subject's normal daily food, individuals were trained to walk on a treadmill. Individuals were habituated to the equipment and then trained in stages over a period of 1 month. Each individual walked on a treadmill for a period of up to $10 \mathrm{~min}$, at different speeds, wearing both a collar (Dog collar, Pets at Home, UK; $53 \mathrm{~g}$ ) and a harness (Adjustable nylon dog harness, Bunty Pet Products, UK; 128 g).

\section{Acceleration data collection}

We used tri-axial accelerometers (Daily Diary tag, Wildbyte Technologies; [19]) that measured acceleration in three orthogonal axes at a sampling rate of $40 \mathrm{~Hz}$. The devices were powered by a Li-Po rechargeable battery (Cameron Sino, HK, $31.54 \times 25.13 \times 3.95 \mathrm{~mm}$; $5.5 \mathrm{~g}$ ), enclosed in plastic casing $(35 \times 45 \times 12 \mathrm{~mm}$; combined mass $15.2 \mathrm{~g}$ ) and attached using waterproof tape (Tesa ${ }^{\circledR}$ tape 4651, Tesa, Germany). One accelerometer was placed on the collar in the ventral position on the subject's neck (Fig. 4); using different combinations of collar sizes, from approximately 3 to $30 \%(+1$ to $+9 \mathrm{~cm})$ larger than individuals' neck sizes, and weights, from 0.4 to $1.2 \%$ (88 to $285 \mathrm{~g}$ ) of individuals' body masses (Table 4). Weight was added adjacent to the accelerometer using metal nuts taped to the collar, with the aim

Table 4 Details of each individual goat (G01-G04) used in the study, including body weight, neck size and age

\begin{tabular}{llll}
\hline Individual & $\begin{array}{l}\text { Body weight } \\
(\mathbf{k g})\end{array}$ & Neck size $(\mathbf{c m})$ & Age \\
\hline G01 & 23.1 & 34 & 8 \\
G02 & 22.5 & 32 & 5 \\
G03 & 15.2 & 29 & 3 \\
G04 & 13.5 & 26 & 3 \\
\hline
\end{tabular}




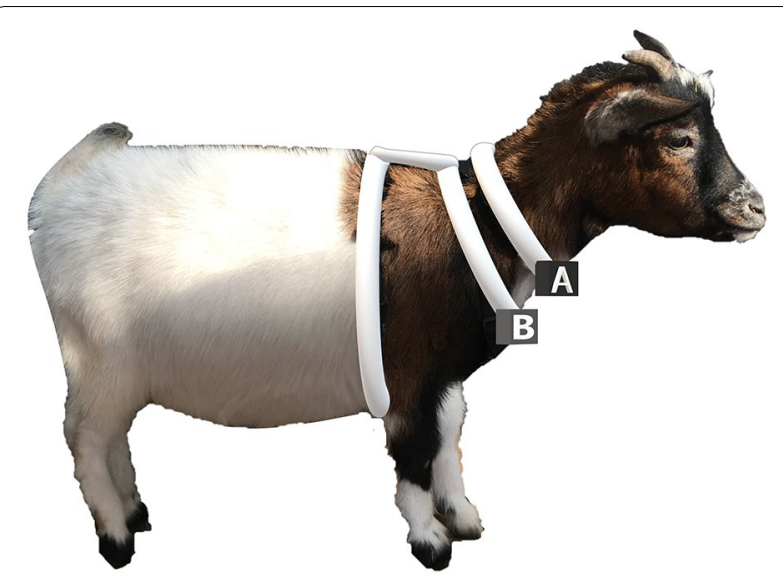

Fig. 4 Goat (G03) with an accelerometer attached to the collar (a) and to the harness $(\mathbf{b})$

of resembling larger battery weight. A second accelerometer was placed on the harness in a ventral position, to act as a control in the same position as the first device. The harness provided a more rigid placement, minimising movement of the accelerometer beyond that of the study animal (Fig. 4). Collar combinations measured were each collar size with the smallest and largest weight, and each collar weight with the tightest and loosest collar (Table 1). After each individual was trained and acclimated to the equipment, each collar combination was tested on each individual once. Collar combinations that tested the largest and smallest collar size with the lightest and heaviest collar weight were measured. Goats walked at speeds between 0.8 and $3.0 \mathrm{~km} / \mathrm{h}$ at increments of $0.2 \mathrm{~km} / \mathrm{h}$ and walking speeds were recorded in a random order, for a minimum duration of $1 \mathrm{~min}$. Each individual was video-recorded during data collection to remove data obtained during behaviours other than walking (Fujifilm XP120, Fujifilm, Japan; 59.94 frame/s). Sections, where the speed of the treadmill was changing $(\sim 15 \mathrm{~s})$, were also removed.

Data were processed and analysed in $\mathrm{R}$ version 3.6.2 [32]. Data were labelled for the corresponding speed, collar size and collar weight. To calculate VeDBA, raw acceleration for each axis was used to derive static acceleration over a running mean of $2 \mathrm{~s}$ and thus the vectoral sum of dynamic body acceleration was calculated (VeDBA) [33]. Mean VeDBA measured over a 1s interval was calculated for the collar- and harnessattached devices. To determine how acceleration measured by the collar changes, the difference between the collar and harness attached devices was also calculated (difVeDBA $\left.=\overline{\mathrm{VeDBA}}_{\text {collar }}-\overline{\mathrm{VeDBA}}_{\text {harness }}\right)$.

\section{Data analysis}

To understand the relationship between collar size and weight on measured acceleration (VeDBA), three separate general linear fixed effect models were used to (1) investigate the VeDBA measured on the collarattached device; (2) investigate the VeDBA measured on the harness-attached device; and (3) investigate the relationship with the difference in VeDBA measured from the two devices (difVeDBA). The fixed variables included in the models were goat ID, walking speed and collar size and weight as categorical variables. A two-way interaction between collar size and weight was included. The two-way interactions between speed and the variables, goat ID, collar size and collar weight, were also included. The global models were simplified using the "dredge" function in the $\mathrm{R}$ package MuMin [34] which uses $\mathrm{AIC}_{\mathrm{c}}$ to assess the best fit model [27]. Models within $\triangle \mathrm{AIC}_{\mathrm{c}} \leq 6$ were retained for inference and the simplest model was selected (Table 2 and Additional file 1) [35]. Model residuals were checked for a normal distribution.

\section{Supplementary information}

Supplementary information accompanies this paper at https://doi. org/10.1186/s40317-020-00198-9.

Additional file 1. The estimated coefficients of variables for each general linear model used: (1) effect of collar size and weight on VeDBA, (2) VeDBA measured by the harness and (3) difference between collar and harness. Bold font indicates that 95\% confidence intervals for coefficients did not overlap zero.

\section{Abbreviations}

VeDBA: Vectoral Dynamic Body Acceleration; difVeDBA: Difference of VeDBA measured on collar and harness; GLM: General Linear Model; AIC ${ }_{c}$ : Akaike Information Criteria.

\section{Acknowledgements}

We thank Belfast Zoo and Belfast City Council for allowing us to conduct this study, and the staff at Belfast Zoo for their help during data collection.

\section{Authors' contributions}

ED, RPW and DMS conceived the study design. ED collected the data. ED and PS analysed the data. ED drafted the manuscript. All authors provided comments. All authors read and approved the final manuscript.

Funding

ED was supported by a Department for Education studentship, Northern Ireland.

\section{Availability of data and materials}

The datasets used and analysed during the current study are available from the corresponding author on reasonable request.

Ethics approval and consent to participate

This study was approved by the Queens University Belfast ethics committee (QUB-BS-AREC-19-004) and Belfast Zoo.

Consent for publication

Not applicable. 


\section{Competing interests}

The authors declare that they have no competing interests.

\section{Author details}

${ }^{1}$ School of Biological Sciences, Queen's University Belfast, 19 Chlorine Gardens, Belfast BT9 5DL, Northern Ireland, UK. ${ }^{2}$ Department of Biosciences, Durham University, South Road, Durham DH1 3LE, England, UK. ${ }^{3}$ Biosciences, College of Science, Swansea University, Singleton Park, Swansea SA2 8PP, Wales, UK.

Received: 18 December 2019 Accepted: 2 March 2020

Published online: 18 March 2020

\section{References}

1. Chmura HE, Glass TW, Williams CT. Biologging physiological and ecological responses to climatic variation: new tools for the climate change era. Front Ecol Evol. 2018;6:1-9.

2. Williams HJ, Taylor LA, Benhamou S, Bijleveld Al, Clay TA, De Grissac S, et al. Optimising the use of bio-loggers for movement ecology research. J Anim Ecol. 2020;89:189-206.

3. Hughey LF, Hein AM, Strandburg-Peshkin A, Jensen FH. Challenges and solutions for studying collective animal behaviour in the wild. Phil Trans R Soc B Biol Sci. 2018:373:1746.

4. Brown DD, Kays R, Wikelski M, Wilson RP, Klimley A. Observing the unwatchable through acceleration logging of animal behavior. Anim Biotelemetry. 2013;1:20.

5. Shepard ELC, Wilson RP, Halsey LG, Quintana F, Laich AG, Liebsch N, et al Derivation of body motion via appropriate smoothing of acceleration data. Aquat Biol. 2008;10:47-60.

6. Williams HJ, Holton MD, Shepard ELC, Largey N, Norman B, Ryan PG, et al. Identification of animal movement patterns using tri-axial magnetometry. Mov Ecol. 2017;5:6

7. Alvarenga FAP, Borges I, Palkovic L, Rodina J, Oddy VH, Dobos RC. Using a three-axis accelerometer to identify and classify sheep behaviour at pasture. Appl Anim Behav Sci. 2016;181:91-9.

8. Pagano AM, Rode KD, Cutting A, Owen MA, Jensen S, Ware JV, et al. Using tri-axial accelerometers to identify wild polar bear behaviors. Endanger Species Res. 2017;32:19-33.

9. Tatler J, Cassey P, Prowse TAA. High accuracy at low frequency: detailed behavioural classification from accelerometer data. J Exp Biol. 2018;221:jeb184085.

10. Fehlmann G, O'Riain MJ, Hopkins PW, O'Sullivan J, Holton MD, Shepard ELC, King AJ. Identification of behaviours from accelerometer data in a wild social primate. Anim Biotelemetry. 2017;5:1-11.

11. Halsey LG, Shepard ELC, Quintana F, Gomez Laich A, Green JA, Wilson RP. The relationship between oxygen consumption and body acceleration in a range of species. Comp Biochem Physiol. 2009;152:197-202.

12. Gleiss AC, Wilson RP, Shepard ELC. Making overall dynamic body acceleration work: on the theory of acceleration as a proxy for energy expenditure. Methods Ecol Evol. 2011:2:23-33.

13. Wilson RP, Börger L, Holton MD, Scantlebury DM, Gómez-Laich A, Quintana $\mathrm{F}$, et al. Estimates for energy expenditure in free-living animals using acceleration proxies: a reappraisal. J Anim Ecol. 2019;80:161-72.

14. Bidder OR, Walker JS, Jones MW, Holton MD, Urge P, Scantlebury DM, et al. Step by step: reconstruction of terrestrial animal movement paths by dead-reckoning. Mov Ecol. 2015;3:23.

15. Hawkins P. Bio-logging and animal welfare: practical refinements. Mem Natl Polar Res Inst. 2004:58:58-68.

16. Wilson RP, McMahon CR. Measuring devices on wild animals: what constitutes acceptable practice? Front Ecol Environ. 2006:4:147-54

17. Coughlin CE, Van Heezik Y. Weighed down by science: do collar-mounted devices affect domestic cat behaviour and movement? Wildl Res. 2014:41:606-14

18. Shillinger GL, Bailey H, Bograd SJ, Hazen EL, Hamann M, Gaspar P, et al Tagging through the stages: technical and ecological challenges in observing life histories through biologging. Mar Ecol Prog Ser. 2018:457:165-70.
19. Wilson RP, Shepard ELC, Liebsch N. Prying into the intimate details of animal lives: use of a daily diary on animals. Endanger Species Res. 2008:4:123-37.

20. Bullock RW, Guttridge TL, Cowx IG, Elliott M. The behaviour and recovery of juvenile lemon sharks Negaprion brevirostris in response to external accelerometer tag attachment. J Fish Biol. 2015;87:1342-54.

21. Graf PM, Wilson RP, Qasem L, Hackländer K, Rosell F. The use of acceleration to code for animal behaviours; a case study in free-ranging Eurasian beavers Castor fiber. PLoS ONE. 2015;10:1-17.

22. Horning M, Andrews RD, Bishop AM, Boveng PL, Costa DP, Crocker DE, et al. Best practice recommendations for the use of external telemetry devices on pinnipeds. Anim Biotelemetry. 2019;7:1-17.

23. Wang Y, Nickel B, Rutishauser M, Bryce CM, Williams TM, Elkaim G, Wilmers CC. Movement, resting, and attack behaviors of wild pumas are revealed by tri-axial accelerometer measurements. Mov Ecol. 2015;3:2.

24. Casper RM. Guidelines for the instrumentation of wild birds and mammals. Anim Behav. 2009;78:1477-83.

25. Brooks C, Bonyongo C, Harris S. Effects of global positioning system collar weight on zebra behavior and location error. J Wildl Manag. 2008:72:527-34.

26. Krausman PR, Bleich VC, Cain JW, Stephenson TR, DeYoung DW, McGrath PW, et al. From the field: neck lesions in ungulates from collars incorporating satellite technology. Wildl Soc Bull. 2004;32:987-91.

27. Burnham KP, Anderson DR. Model selection and multimodel inference: a practical information-theoretic approach. New York: Springer; 2002.

28. Hellgren EC, Carney DW, Garner NP, Vaughan MR. Use of breakaway cotton spacers on radio collars. Wild Soc Bull. 1988:16:216-8.

29. Gedir JV. A non-invasive system for remotely monitoring heart rate in free-ranging ungulates. Anim Welf. 2001;10:81-9.

30. Aldridge HDJN, Brigham RM. Load carrying and maneuverability in an insectivorous bat: a test of the $5 \%$ "rule" of radio-telemetry. J Mammal. 1988;69:379-82.

31. Phillips RA, Xavier JC, Croxall JP. Effects of satellite transmitters on albatrosses and petrels. Auk. 2003;120:1082-90.

32. R Core Team. R: a language and environment for statistical computing. Vienna, Austria: R Foundation for Statistical Computing; 2019. https:// www.r-project.org/.

33. Qasem L, Cardew A, Wilson A, Griffiths I, Halsey LG, Shepard ELC, et al. Tri-axial dynamic acceleration as a proxy for animal energy expenditure; should we be summing values or calculating the vector? PLoS ONE. 2012; 7:e31187

34. Barton K. MuMIn: multi-model inference. R package version 1.42.1. 2018. https://CRAN.R-project.org/package=MuMIn.

35. Richards SA, Whittingham MJ, Stephens PA. Model selection and model averaging in behavioural ecology: the utility of the IT-AIC framework. Behav Ecol Sociobiol. 2011;65:77-89.

\section{Publisher's Note}

Springer Nature remains neutral with regard to jurisdictional claims in published maps and institutional affiliations.

Ready to submit your research? Choose BMC and benefit from

- fast, convenient online submission

- thorough peer review by experienced researchers in your field

- rapid publication on acceptance

- support for research data, including large and complex data types

- gold Open Access which fosters wider collaboration and increased citations

- maximum visibility for your research: over 100M website views per year

At $\mathrm{BMC}$, research is always in progress.

Learn more biomedcentral.com/submissions 